\title{
INDEX OF DENTISTS
}

A

Anderson, Mr., 314

Ash, Mr., 538, 645

B

Barclay, Mr., 372

Bell, Mr., 484, 760, 807, 859

Bigg, Mr., 673-675, 696, 715, 760, 802, 829, 837,

$876-877,882,886,897,904,910,917$

C

Canton, 417-418

Canton, Mr., 230, 293, 324, 330, 338-339, 345 ,

$358,369,375-376,380,394,397-399,407,410$, $420-421,426,436,442,452-454,462,473,475$, $480,485,488,491,493,496,505,518,523,528$, $537,540-541,549-550,558,571,601,606,617$, $624-625,629,636,640,647,651,659,663,684$, $696,711,713,718,721,727,731,735,758,760$, $767,790,810,837,839,842,853,855,872$,

878-879, 897, 912-913

Canton, Mr. A., 278, 280, 286

Canton, Mr. Alfred, 222, 243, 279, 289, 843

Canton, Mr. W. F., 764

Cartwright, Mr., 421, 461, 472, 504, 527, 531, 536, $547,549,554,557,577,582,629,632,637$, $639-640,652,670,703,712,742,746,856-857$, $874,879-880,885,902,906,915,918$

Cartwright, Jnr., Mr., 453, 478, 486

Cartwright, Mr. S., 518, 528, 558, 610, 630, 639, $643,663,671,695,729,746-747,769,795,805$, 840,875

Cartwright, Mr. Sam'1, 666, 708

Cattlin, Mr., 250, 369, 482-483

Clark, Mr., 242

Clarke, assistant of Mr., 89

Clarke, Mr., 43, 89, 244, 255, 721

Clendon, Mr., 424

Cook, Mr., 646

Cook, Mr. Augustus, 645

Cooke, Mr. Aug., 700

Crampten, Mr., 156, 214, 292, 295, 487, 489, 524, $608,610,627,632,635,637,644-645,659,684$, $692,705,738,779,870-871,889,908$

D

dentist, un-named, 339, 578

E

Eden, Mr., 202, 292, 324, 384, 641
F

Featherstone, Mr., 290, 607, 628, 860

Fletcher, Mr., 49, 247, 349, 383, 399, 404, 428, 451, $461,478,485,519,532,535,538,568,606,629$, $640,642,658,703,742,763,795,800,804,809$, $825,846,849$

G

George, Mr., 327

Gilbert, Mr., 562

Gregson, Mr., 834, 844

$\mathrm{H}$

Hampson, Mr., 34, 228, 543-544

Harrison, Mr., 128, 176, 189

Hartry, Mr., 656, 664, 742

Heath, Mr., 545, 751

Hepbum, Mr., 427, 571, 810

Hockley, Mr., 727

I

Ibbotson, Mr., 879

$\mathrm{J}$

Jarman, Mr., 835

Jones, Mr., 633

K

Kempton, Mr., 63, 291, 372, 423, 630, 634, 740 , 789

L

Lintott, Mr., 21, 65, 84, 380, 386, 392, 407, 413, $447,456,473,635-636,659,675,692,743,758$, $831,850,856,866-867,888$

Lukyn, Mr., 626

M

May, Mr., 756

Merryweather, Mr., 810

Moseley, Mr. Ephraim, 495

N

Napier, Mr., 900

Nasmyth, Mr., 233, 356, 373, 483, 566, 587, 657, 693

Nasmyth, partner of Mr., 693

Normansell, Mr., 568, 583, 759, 906 


\section{Index of Dentists}

$P$

Parkington, Mr., 380

Parkinson, Mr., 743, 855, 896

Pedley, Mr., 403

$\mathbf{R}$

Rahn, Mr., 627, 841, 874, 895, 916-917, 919

Robinson, Mr., 50, 56, 358, 493-494, 531, 554 , $594-595,645,666,710$

Rogers, Mr., 41, 51, 127, 198, 255, 259, 327, 331, $333,342-343,349,352-353,362-363,374$, $380-381,388,391,393-394,396,408,410,415$, $421,430,447,468-469,512,531,551,553-554$, $562,578,584,603,626,637,640,664,683,690$, $693,713,723$

Rogers, Mr. A., 439, 441, 447, 459, 473, 476, 479, $482-483,485,488,490,493,505,515-516,519$, $521,524,526,532,538,546,559-560,564,566$, $567,577,581-582,595,599,617,620-622,626$, $633,636,647,664,671,679-680,686,688,693$, $709,772,825,829-830,842-843,847,874$, 909-910

Rogers, Mr. Arnold, 474, 709

Rogers, Mr. C. A., 367

Rogers, Mr. Chas., 566

Rogers, Mr. Chs. A., 412

Rogers, Mr. F., 450, 479, 514, 548

Rogers, Mr. F. W., 475, 572, 575, 598, 625, 631, $647,658,672,726,734,737,739,770,775-776$. $788-790,805,808,841,843,847,852,866,872$, $875,897,899,904,908,912$

Rogers, Mr. Fred. W, 831

Rogers, Mr. T., 559

Rogers, Mr. T. A., 504-505, 519-520, 531, 534, $537,539-541,544,547,549-550,556,559-560$, $566,575,587,593,595,635-636,641-643,658$, $662-663,666,669-671,676-677,681-682$, $684-685,687-690,692,697,703,708,717,719$. $722,725,729,734,738,750,766-767,769,771$, $791,794,797,807,854,899$

Rogers, Mr. Thos., 582, 605, 608-609, 614, 623, $626,630-631,698,706-707,709-710,713,749$, $764,879,881,899,911$

Rogers, Mr. Thos. A., 459, 476, 480, 605-606, 648, $686,700,753,762,810,833,835,858,894,901$, $903,907,915$

Rogers, Mr. W. F., 634, 680, 788, 860, 895
$S$

Salter, Mr., 527, 802, 838, 904

Saunders, Mr., 121, 446, 511, 640, 689, 693, 698, $702,705,707,709-710,712,715,725,727-730$, $733-735,738-739,741,745,759,765,768-769$, $784,787,789,795,797-799,801,803-804$, $806-807,810,825,829-831,835-839,841-842$, $846,852,861-862,865,867,869,873-874,876$, $878,880-881,884-885,889,897,901,907-912$, 914-918

Scott, Mr., 601, 636, 700, 843

Sercombe, Mr., 352, 362-363, 463, 622, 852,

$857-858,860,864,901$

Sheffield, Mr., 553

T

Tomes, Mr., 277, 429-430, 473, 484-485, 512, 539, $564,621-622,632,670,706,731,746,758,858$, 862

Truman, Mr., 518, 564, 605, 648-649, 659, 684, $707,773,902$

$\mathrm{U}$

un-named dentists, 339,578

see also un-named practitioners, 575

V

Vanderpant, Mr., 738

Vasey, Mr., 797, 844, 860, 863

W

Waite, Mr., 379, 402, 460

Walker, Mr., 588

Watts, Mr. Townly, 642

West, assistant of Mr., 721

West, Mr., 357, 425-426, 450, 463, 499, 503, $512-513,540,544,551,578,595,604,617,627$. $638,669,716,721,727,729,788-789,852,858$, $866,873,888,908,918$

West, Mr. B., 693

Winterbottom, Mr., 776

Woodhouse, Mr., 387, 573, 610-611, 683, 786, 790, $886-887,890,894,904,911,913$ 